\title{
The Regulation Effect of Social Support in Relation to Maternal Adaptation and Maternal Role Strain in Primipara Mothers
}

\author{
Sun Mi Kim \\ Lecturer, College of Nursing, Chungnam National University, Daejeon, \\ The Republic of Korea \\ Sunmik204@gmail.com
}

\begin{abstract}
This study was conducted to confirm the regulation effect of social support in the relationship between primipara mother's maternal role strain and maternal adaptation. The participants were 250 primipara mothers in S City and J Province, and data were collected using the URL in mobile devices from November to December 2018. For the analysis, the following tools were used: maternal adaptation questionnaire (MAQ) for maternal adaptation, maternal role strain developed by Hobbs and Steffensmeier modified by Kho, and multidimension scale on social support developed by Zimet and Farley. Using SPSS 21.0, the collected data were analyzed through t-test, ANOVA, Scheffé test, Pearson's correlation coefficient, and Hayes' PROCESS macro program. Among the general characteristics, the woman's level of self-identity was significant in the postpartum care program, feeding method, and baby care assistance. Perception of the mother's role was significant in the postpartum care program. Higher maternal role strain resulted in the woman's lower level of self-identity $(\beta=-0.44, p<0.001)$ and perception of the mother's role $(\beta=-0.39, p<0.001)$. Also, social support was identified as a significant regulatory effect only about the perception of the mother's role among maternal role strain and maternal adaptation $(p=0.004)$. Therefore, regarding maternal adaptations, social support such as emotional support and nurturing process guidance should be provided to enhance the perception of the mother's role. Additional research should be conducted on the regulation effect to increase the woman's level of selfidentity in maternal adaptation.
\end{abstract}

Keywords: Mothers, Social support, Adaptation, Maternal

\section{Introduction}

Korea has the lowest fertility rate among OECD member countries, leading to various social problems [1]. The period of childbirth is one of the most dynamic periods of a woman's entire life cycle, and after childbirth, difficulties arise due to physical changes, psychological changes, and responsibility for raising children [2]. When women perceive the parenting process positively, their confidence and satisfaction are strengthened, and because they feel satisfied with their maternal role, they have a positive effect on pregnancy and childbirth in the future and this can help solve the problem of low birthrate [3].

\section{Background}

Article history:

Received (March 12, 2021), Review Result (April 14, 2021), Accepted (July 10, 2021) 
Maternal adaptation is a concept that encompasses various adaptations of mothers from the psychological, relational, behavioral, and cognitive dimensions and can be divided into women's self-identity and woman's role perception motherhood of maternal role strain [4]. The primipara mothers are expected to play the role of a caregiver but as they experience physical and mental difficulties in the parenting process, tension about their maternal role strain increases [5].

Maternal role strain causes emotional imbalance due to negative parenting awareness of the primipara mothers, negatively affects the child's development and family life, and negatively influences the next childbirth [6]. A previous study suggested that social support is a regulation factor that reduces the maternal roles strain among mothers [6], study reported that various social supports played a positive role, in accelerating children's development, because these promote the mother's maternal confidence, psychological stability, and life satisfaction [7].

In the previous studies on maternal adaptation, only the roles of mothers, relations of children, parenting stress [10], and interactions with children were discussed, with a focus on parenting for women's role perception of motherhood and women's self-identity [4][8][9].

There was no study that women self-identify and women's role perception of motherhood variables that can be controlled through on changed maternal role strain. Therefore, this study intended to provide basic data that may help the primipara mothers adapt to the parenting process through social support in the relationship between the maternal role strain and maternal adaptation.

\section{Method}

\subsection{Research design}

This study is a descriptive research study to confirm the regulation effect of social support in the relationship between maternal role strain and maternal adaptation in primipara mothers.

\subsection{Research subject}

The subjects who were eligible for participation in this study were primipara mothers: within six months of giving birth to a normal infant. To calculate the number of samples required for this study, the $\mathrm{G}^{*}$ power3.1.4 program was used to determine the appropriate number of sample sizes required for regression analysis (effect size $\mathrm{f} 2=.10$, significance level $\alpha=.05$, power $(1-\beta)$ =95). Based on the calculations, the minimum sample size should be 246 people, but considering that there may be dropouts from the study, the questionnaire was distributed to 280 people. Finally, a total of 250 subjects was analyzed.

\subsection{Research tool}

\subsubsection{General characteristics}

General characteristics included age, educational background, economic status, occupational status, planned pregnancy, participation in prenatal education programs, postpartum blue, feeding methods, and baby's care assistance. As for the general characteristics of the subjects of this study, most of the subjects were in their 30s (204 persons, $81.6 \%$ ) and most of the subjects were college graduates (200 persons, $80 \%)$. Monthly income (10,000 won) was similar with 60 subjects $(24.0 \%)$ under 300 won, 62 subjects (24.8\%) under 300-399 won, 59 subjects (23.6\%) under 400-499won, and 69 subjects (27.6\%) over 500won. 112 subjects (44.8\%) were 
on leave. The majority of the subjects had planned pregnancy 168 subjects $(67.2 \%)$ while 147 subjects $(58.8 \%)$ participated in the prenatal education program during pregnancy. 147 subjects $(58.8 \%)$ said they did not experience postpartum blue after childbirth. Feeding method, 98 subjects (39.2\%) used bottle feeding, 85 subjects (34.0\%) used mixed feeding, and 67 subjects (26.8\%) breastfeeding their babies. Majority of the mothers administered infant formula to their babies. In addition, 166 subjects $(66.4 \%)$ did not have any baby care assistance for their children [Table 1].

\subsubsection{Maternal role tension}

Maternal role strain was measured by the tools of Hobbs and Steffensmeier, modified by Kho [11]. This tool is a four-point scale of a total of 20 questions, and the higher the score, the higher the maternal role strain of the primipara mother. The reliability of the tool Cronbach's $\alpha$ was found to be .86 .89 in Kho [11] and .87 in this study.

\subsubsection{Social support}

For social support, Zimet and Farley's multi-dimension scale of Perceived Social support was adapted by Park Ji-won and measured by a tool modified by Shin and Jung [12]. This tool is a five-point scale with a total of 25 questions, which means that the higher the score, the more the mother thinks that she is getting help for parenting around her. The reliability of the tool Cronbach's $\alpha$ was .94 at the time of Park Ji-won's development and was found to be .91 in this study.

\subsubsection{Maternal adaptation}

Maternal adaptation was measured by a tool modified and supplemented by Choi [13] of the Maternal Adaptation Questionnaire (MAQ) developed by Sheehan. This tool is a four-point scale of 35 questions in total. According to the criteria classified in the study of Ahn and Kim [10], the woman's self-identity domain (15 questions) and the role of a mother is a time when primipara mothers need to establish a new ego. It consists of a woman's role perception of the motherhood area (20 questions) that forms a sense of duty. The higher the score, the higher the degree of adaptation to maternal role perception of motherhood. The reliability of the tool Cronbach's $\alpha$ was 0.79 in Choi's study [13], and in this study, the woman's self-identity area was 0.71 , the woman's role perception of motherhood area was 0.61 , and the reliability for all items was .78.

\subsection{Data collection}

This study was conducted after deliberation and approval (approval number: MC18QEI0090) by C University Institutional Review Board, and the data collection period was from November 7 to December 31, 2018. Data was collected at obstetrics and gynecology hospitals and public health centers located in $\mathrm{S}$ and $\mathrm{J}$ regions. The researcher explained the purpose and method of the study to the subjects while the data was collected from the consenting subjects by using a URL (uniform resource locator).

The data collected in this study were analyzed using SPSS 22.0. The following were conducted: t-test, ANOVA, Scheffé test, Pearson's correlation coefficient. The regulation effect was statistically analyzed using the PROCESS macro ver. 3.4.

\subsection{Results}




\subsubsection{General characteristics of the subject}

General characteristics included age, educational level, economic status, monthly income, planned pregnancy, attend postpartum care program, postpartum blue, feeding method, and baby's care assistance. As for the general characteristics of the subjects of this study, most of the subjects were in their 30s (204 persons, 81.6\%) and most of the subjects were college graduates (200 persons, $80 \%)$. Monthly income (10,000 won) was similar with 60 subjects (24.0\%) under 300 won, 62 subjects (24.8\%) under 300-399 won, 59 subjects (23.6\%) under $400-499$ won, and 69 subjects $(27.6 \%)$ over 500won. 112 subjects $(44.8 \%)$ were on leave. The majority of the subjects had planned pregnancy 168 subjects $(67.2 \%)$ while 147 subjects (58.8\%) participated in the prenatal education program during pregnancy. 147 subjects $(58.8 \%)$ said they did not experience postpartum blue after childbirth. Feeding method, 98 subjects (39.2\%) used bottle feeding, 85 subjects (34.0\%) used mixed feeding, and 67 subjects $(26.8 \%)$ breastfeeding their babies. Majority of the mothers administered infant formula to their babies. In addition, 166 subjects $(66.4 \%)$ did not have any baby care assistance for their children [Table $1]$.

Table 1. General characteristics of participants $(\mathrm{N}=250)$

\begin{tabular}{|c|c|c|}
\hline Characteristics & Categories & $\mathrm{N}(\%)$ \\
\hline \multirow{3}{*}{ Age (year) } & $20 \mathrm{~s}$ & $34(13.6)$ \\
\hline & $30 \mathrm{~s}$ & 204(81.6) \\
\hline & $40 \mathrm{~s}$ & $12(4.8)$ \\
\hline \multirow{3}{*}{ Education level } & High school & $13(5.2)$ \\
\hline & College & $200(80.0)$ \\
\hline & Graduate School & $37(14.8)$ \\
\hline \multirow{4}{*}{ Monthly income (10,000 won) } & $<299$ & $60(24.0)$ \\
\hline & $300-399$ & $62(24.8)$ \\
\hline & $400-499$ & $59(23.6)$ \\
\hline & $\geq 500$ & $69(27.6)$ \\
\hline \multirow{3}{*}{ Plan for employment state } & Suspension & $112(44.8)$ \\
\hline & Resign & $82(32.8)$ \\
\hline & Housewife & $56(22.4)$ \\
\hline \multirow{2}{*}{ Planned pregnancy } & Yes & $168(67.2)$ \\
\hline & No & $82(32.8)$ \\
\hline \multirow{2}{*}{ Attend postpartum care program } & Yes & $160(64.0)$ \\
\hline & No & $90(36.0)$ \\
\hline \multirow{2}{*}{ Postpartum blues } & No & $147(58.8)$ \\
\hline & Yes & $103(41.2)$ \\
\hline \multirow{3}{*}{ Feeding method } & Breastfeeding & $67(26.8)$ \\
\hline & Bottle feeding & 98(39.2) \\
\hline & Mixed & $85(34.0)$ \\
\hline \multirow{2}{*}{ Baby's care assistance } & No & $166(66.4)$ \\
\hline & Yes & $84(33.6)$ \\
\hline
\end{tabular}

\subsubsection{Differences between general characteristics of the subject and maternal adaptation}


The woman's level of self-identity areas (according to the general characteristics of the subjects of this study) that were found to be statistically significant were: Attend postpartum care program $(\mathrm{t}=2.25, p=0.025)$; Feeding method $(\mathrm{F}=5.17, p=0.006)$; and Baby's care assistance $(\mathrm{t}=-2.10, p=0.036)$. It was found out that primipara mothers who participated in the attend postpartum care program during pregnancy and the primipara mothers who did not have a baby's care assistance had a high level of woman's level of self-identity.

Moreover, according to the results of Scheffé's post-test on method, woman's level of selfidentity areas was high in the order of bottle feeding, mixed feeding, and breastfeeding [Table 2]. It was found out that women's role perception of motherhood area was high in primipara mothers who participated in attend postpartum care programs during pregnancy $(\mathrm{t}=2.58$, $p=0.010$ ). There was no significant difference in maternal adaptation according to other general characteristics [Table 2].

Table 2. Differences in a maternal adaption by general characteristics

\begin{tabular}{|c|c|c|c|c|c|}
\hline \multirow{2}{*}{ Characteristics } & \multirow{2}{*}{ Categories } & \multicolumn{2}{|c|}{$\begin{array}{c}\text { Woman's level of self- } \\
\text { identity }\end{array}$} & \multicolumn{2}{|c|}{$\begin{array}{l}\text { Woman's role perception of } \\
\text { motherhood }\end{array}$} \\
\hline & & $\mathrm{M}(\mathrm{SD})$ & $\mathrm{t} / \mathrm{F}(\mathrm{p})$ & $\mathrm{M}(\mathrm{SD})$ & $\mathrm{t} / \mathrm{F}(\mathrm{p})$ \\
\hline \multirow{3}{*}{ Age (year) } & $20 \mathrm{~s}$ & $43.26(4.79)$ & \multirow{3}{*}{$\begin{array}{c}0.82 \\
(0.440)\end{array}$} & $57.15(5.08)$ & \multirow{3}{*}{$\begin{array}{c}0.19 \\
(0.828)\end{array}$} \\
\hline & $30 \mathrm{~s}$ & $43.71(4.75)$ & & $57.74(5.30)$ & \\
\hline & $40 \mathrm{~s}$ & $42.00(4.02)$ & & $57.50(4.08)$ & \\
\hline \multirow{3}{*}{ Education level } & High school & $44.92(3.57)$ & \multirow{3}{*}{$\begin{array}{c}0.76 \\
(0.467)\end{array}$} & $56.15(5.68)$ & \multirow{3}{*}{$\begin{array}{c}0.69 \\
(0.500)\end{array}$} \\
\hline & College & $43.41(4.76)$ & & $57.65(5.08)$ & \\
\hline & Graduate School & $43.95(4.90)$ & & $58.14(5.74)$ & \\
\hline \multirow{4}{*}{$\begin{array}{l}\text { Monthly income } \\
\text { (10,000 won) }\end{array}$} & $<299$ & $44.08(5.20)$ & \multirow{4}{*}{$\begin{array}{c}0.40 \\
(0.756)\end{array}$} & $57.67(5.87)$ & \multirow{4}{*}{$\begin{array}{c}0.82 \\
(0.486)\end{array}$} \\
\hline & $300-399$ & $43.47(4.88)$ & & $58.13(5.33)$ & \\
\hline & $400-499$ & $43.15(4.80)$ & & $56.76(4.80)$ & \\
\hline & $\geq 500$ & $43.57(4.11)$ & & $57.94(4.82)$ & \\
\hline \multirow{3}{*}{$\begin{array}{c}\text { Plan for employment } \\
\text { state }\end{array}$} & Suspension & $43.50(4.71)$ & \multirow{3}{*}{$\begin{array}{c}1.09 \\
(0.337)\end{array}$} & $57.55(5.07)$ & \multirow{3}{*}{$\begin{array}{c}0.03 \\
(0.968)\end{array}$} \\
\hline & Resign & $44.11(4.48)$ & & $57.74(4.75)$ & \\
\hline & Housewife & $42.91(5.08)$ & & $57.68(6.14)$ & \\
\hline \multirow{2}{*}{ Planned pregnancy } & Yes & $43.74(4.64)$ & \multirow{2}{*}{$\begin{array}{c}0.84 \\
(0.400) \\
\end{array}$} & $58.00(5.30)$ & \multirow{2}{*}{$\begin{array}{c}1.55 \\
(0.122)\end{array}$} \\
\hline & No & $43.21(4.91)$ & & $56.91(4.97)$ & \\
\hline \multirow{2}{*}{$\begin{array}{l}\text { Attend postpartum care } \\
\text { program }\end{array}$} & Yes & $44.07(4.72)$ & \multirow{2}{*}{$\begin{array}{c}2.25 \\
(0.025)\end{array}$} & $58.28(5.24)$ & \multirow{2}{*}{$\begin{array}{c}2.58 \\
(0.010) \\
\end{array}$} \\
\hline & No & $42.68(4.62)$ & & $56.52(4.98)$ & \\
\hline \multirow{2}{*}{ Postpartum blues } & No & $43.57(4.70)$ & \multirow{2}{*}{$\begin{array}{c}-0.01 \\
(0.989)\end{array}$} & $57.56(5.51)$ & \multirow{2}{*}{$\begin{array}{c}0.31 \\
(0.755)\end{array}$} \\
\hline & Yes & $43.56(4.79)$ & & $57.77(4.76)$ & \\
\hline \multirow{3}{*}{ Feeding method } & Breastfeeding & $42.57(5.05)$ & \multirow{3}{*}{$\begin{array}{c}5.17 \\
(0.01) \\
(b>c>a)\end{array}$} & $57.42(5.24)$ & \multirow{3}{*}{$\begin{array}{c}1.49 \\
(0.227)\end{array}$} \\
\hline & Bottle feeding & $44.72(4.71)$ & & $58.33(5.07)$ & \\
\hline & Mixed & $43.02(4.22)$ & & $57.04(5.30)$ & \\
\hline \multirow{2}{*}{ Baby's care assistance } & No & $44.01(4.53)$ & \multirow{2}{*}{$\begin{array}{c}-2.10 \\
(0.036)\end{array}$} & $57.81(5.03)$ & \multirow{2}{*}{$\begin{array}{l}-.70 \\
(0.487)\end{array}$} \\
\hline & Yes & $42.69(4.99)$ & & $57.32(5.56)$ & \\
\hline
\end{tabular}

\subsubsection{Correlation with the subject's maternal role tension, social support, and maternal adaptation}


The correlation between Maternal role strain, social support, Woman's level of self-identity, and Woman's role perception of motherhood was analyzed with the following results: maternal role strain and social support $(\mathrm{r}=-0.786, p<0.001)$, woman's level of self-identity $(\mathrm{r}=-0.746$, $p<0.001)$ and woman's role perception of motherhood ( $\mathrm{r}=-0.681, p<0.001)$ showed a negative correlation. Social support showed a positive correlation with woman's level of self-identity $(\mathrm{r}=0.636, p<0.001)$ and woman's role perception of motherhood $(\mathrm{r}=0.579, p<0.001)$. A woman's level of self-identity showed a positive correlation with a woman's role perception of motherhood $(\mathrm{r}=0.577, p<0.001)$ [Table 3].

Among the maternal adaptation classification, a Woman's level of self-identity averaged $43.57( \pm 4.72)$ points, and a Woman's role perception of motherhood averaged $57.64( \pm 5.21)$ points. The average maternal role strain was $51.30( \pm 7.94)$ points, and the average social support was $47.12( \pm 8.38)$ points [Table 3$]$.

Table 3. Correlations among variables

\begin{tabular}{|c|c|c|c|c|}
\hline \multirow[t]{2}{*}{ Characteristics } & \multirow[t]{2}{*}{$\mathrm{M}(\mathrm{SD})$} & $\begin{array}{c}\text { Maternal } \\
\text { role strain }\end{array}$ & $\begin{array}{c}\text { Social } \\
\text { support }\end{array}$ & $\begin{array}{c}\text { Woman's level of } \\
\text { self-identity }\end{array}$ \\
\hline & & \multicolumn{3}{|c|}{$\mathrm{r}(p)$} \\
\hline Maternal role strain & $51.30(7.94)$ & 1 & & \\
\hline Social support & $47.12(8.38)$ & $-.796 * * *$ & 1 & \\
\hline Woman's level of self-identity & $43.57(4.72)$ & $-.746 * * *$ & $.636 * * *$ & 1 \\
\hline $\begin{array}{l}\text { Woman's role perception of } \\
\text { motherhood }\end{array}$ & $57.64(5.21)$ & $-.681 * * *$ & $.579 * * *$ & $.577 * * *$ \\
\hline
\end{tabular}

\subsubsection{Regulation effect of social support in the relationship between the maternal role tension and Maternal adaptation classification}

Researchers in this study used Hayes' PROCESS macro program to analyze the regulation effects of social support in the relationship between maternal role strain and maternal adaptation.

As a result of the analysis, the independent variables of the two dependent variables, maternal role strain and the woman's role perception of motherhood, showed significant negative effects. It was confirmed that social support had a mitigating effect in the relationship between maternal role strain and woman's role perception of motherhood recognition domain [Table 4].

Table 4. Effect of social support on the relationship between maternal role strain and maternal adaptation

\begin{tabular}{|c|c|c|c|c|c|c|}
\hline \multirow{2}{*}{\begin{tabular}{c}
$*$ \\
\multirow{2}{*}{ Characteristics }
\end{tabular}} & \multicolumn{6}{|c|}{ Maternal adaptation } \\
\cline { 2 - 7 } & \multicolumn{2}{|c|}{$\begin{array}{c}\text { Woman's role perception of } \\
\text { motherhood }\end{array}$} & \multicolumn{3}{c|}{ Woman's level of self-identity } \\
\cline { 2 - 7 } & $\beta$ & SE & $\mathrm{p}$ & $\beta$ & $\mathrm{SE}$ & $\mathrm{p}$ \\
\hline (Constant) & 57.78 & 0.88 & $<0.001$ & 43.62 & 1.02 & $<0.001$ \\
\hline Maternal role strain & -0.44 & 0.05 & $<0.001$ & -0.39 & 0.04 & $<0.001$ \\
\hline Social support & -0.01 & 0.05 & 0.757 & 0.03 & 0.04 & 0.452 \\
\hline $\begin{array}{c}\text { Maternal role strain*Social } \\
\text { support }\end{array}$ & 0.01 & 0.01 & 0.004 & 0.01 & 0.00 & 0.284 \\
\hline Attend postpartum care program & 0.22 & 0.51 & 0.660 & -0.12 & 0.43 & 0.777 \\
\hline
\end{tabular}




\begin{tabular}{|c|c|c|c|c|c|c|}
\hline Baby's care assistance & - & - & - & 0.04 & 0.43 & 0.914 \\
\hline Breastfeeding & - & - & - & 0.39 & 0.52 & 0.446 \\
\hline Mixed feeding & - & - & - & 0.26 & 0.51 & 0.617 \\
\hline & \multicolumn{2}{|l|}{$\mathrm{R} 2=0.70, \mathrm{~F}=57.67, \mathrm{p}<0.001$} & \multicolumn{2}{|l|}{$\mathrm{R} 2=0.75, \mathrm{~F}=44.85, \mathrm{p}<0.001$} \\
\hline
\end{tabular}

\section{Conclusion}

This study was conducted to confirm the regulation effect of social support in the relationship of maternal role strain and maternal adaptation among primipara mothers. Maternal role strain had an effect on a woman's level of self-identity and woman's role perception of motherhood, which are sub-domains of maternal adaptation. Social support was identified as a regulation factor in the relationship between maternal role strain.

The maternal role strain of primipara mothers harmed woman's level of self-identity, Thus, when maternal role strain was high, the woman's level of self-identity domain decreased. These results supported the results of the study by Kim and Kim [14]. It is necessary to recognize that self-awareness, including self-esteem and sense of efficacy, is a part that changes in the process of performing all developmental tasks. Moreover, self-esteem programs should be provided to primipara mothers to increase their sense of self-identity. The maternal role strain of primipara mothers harmed the woman's role perception of motherhood; when maternal role strain increased, the woman's maternal role perception of motherhood primipara mothers decreased.

These results supported the findings of Song and Ko [15] that mothers with high parenting stress decreased maternal adaptation. Therefore, to promote maternal adaptation, the emotional aspects of the mother, such as self-identity and self-efficacy, should be included in the parenting education program that includes practical caring knowledge and skills education for children.

Lastly, social support was found to mitigate the negative influence of the maternal role strain of primipara mothers on woman's role perception of motherhood. These results supported the findings of the study of Gao et al [16] about postpartum mental education programs that promoted the mothers' mental health status and adaptation to motherhood. Although the spouse has a very significant role in the social support system [15], it is necessary to reduce the tension of the mother as a caregiver by providing other forms of social supports.

This study had limitations in that it was a self-reported survey thorough convenience sampling and did not include various groups of primipara mothers like infertile women. Therefore, it is necessary to conduct a future study involving various groups and identify moderating variables that can improve the self-identity of mothers.

\section{Discussion}

This study was conducted to confirm the regulation effect of social support in maternal adaption and maternal role strain in primipara mothers. Regarding maternal role strain and maternal adaptation of mothers, social support was found to be a significant regulation variable in a woman's role perception of motherhood among the sub-items of maternal adaptation. To raise the maternal adaptation of the on maternal role strain of the primipara mothers, the childrearing education program should include the emotional part of the caregiver and various support systems provided during the child-rearing process.

\section{References}

[1] National Statistical, “2018 Birth statistics(confirmed)," Nationally Approved Statistics, http://kostat.go.kr/portal/-eng/pressReleases/8/10/index.board 
[2] F. Abbaszadeh, M. K. Atrian, N. M. Alavi, A. Bagheri, Z. Sadat, and Z. Karimian, "Relationship between the quality of life and depression in pregnant women," Journal of Nursing and Midwifery Studies, vol.2, no.2, pp.193-197, (2013)

[3] J. H. Hyun, "The influence of spouse support and social support on parental care and general stress," The Korea Association of Child Care and Education, vol.124, pp.45-66, (2019) DOI: 10.37918/kce.2020.09.124.45

[4] J. E. Song and J. A. Ahn, "Effect of intervention programs for improving maternal adaptation in Korea: Systematic review," Korean Journal of Women Health Nursing, vol.19, no.3, pp.129-141, (2013), DOI: 10.4069/kjwhn.2013.19.3.129

[5] Y. J. Cho and S. K. You, "Study on the mediating effect of problem-focused coping and depression in the relations of social support and work-family conflict/enhancement among Korean working mothers," Journal of Counseling and Psychotherapy, vol.24, no.2, pp.441-463, (2012)

[6] S. Y. Bae and C. K. Lee, "The structural relationships among online community use as online leisure, social support, work-family spillover, and quality of life among working mothers," Journal of hospitality and tourism academe, vol 28, no.4, pp.113-128, (2019) DOI: 10.24992/KJHT.2019.06.28.04.113

[7] N. Emmanuel, S. J. Winsome, and B. Claire, "Maternal role development: the impact of maternal distress and social support following childbirth," Midwifery, vol.27, no.2, pp.265-272, (2011) DOI: 10.1016/j.midw.2009.07.003

[8] Y. W. Bae and K. L. Yu, "The relationship between basic psychological needs and postpartum depression: Focused on the mediating effects of spousal support and marital satisfaction," Journal of the Korea Contents Association, vol.21, no.3, pp.518-528, (2021)

[9] G. J Jang, S. Y. Jang, and Y. R. Hong, "The effects of mother-infant interaction program on breast-feeding rate, infant temperament and maternal self-esteem,” Journal of Korean Data and Information Science Society, vol.29, no.1, pp,141-151, (2018)

[10] S. H. Ahn and Y. M. Kim, “Association of parenting stresses, maternal role adjustment, and types of feeding during hospital stays at birth to breastfeeding adaptation," Korean Journal of Women Health Nursing, vol.21, no.4, pp.267-271, (2015) DOI: 10.4069/kjwhn.2015.21.4.262

[11] H. J. Kho, "Strengthening the role of mothers and mothers according to whether they have a job or not and forming a relationship with mother," Seoul: Ewha Woman's University Publisher, (1995)

[12] S. J. Shin and M. J. Jung, "Effects of stress, social support and efficacy on mother's parenting behaviors," Child Health Nursing Research, vol.19, no.1, pp.27-42, (1998)

[13] Y. S. Choi, "Adaptation of maternal roles and postpartum depression of primiparas during the early postpartum period," Seoul: Ewha Woman's University Publisher, (2005)

[14] J. K. Kim and H. R. Kim, "Effects of a mother's characteristics and self-awareness upon parenting stress," Korean Journal of Child Studies, vol.33, no.2, pp.129-144, (2012) DOI: 10.5723/KJCS.2012.33.2.129

[15] J. E. Song and J. M. Ko, "Influencing factors on maternal role adjustment among the primipara women in the first year after childbirth," Journal of the Korean Society of Maternal and Child Health, vol.20, no.3, pp.284296, (2016) DOI:10.21896/jksmch.2016.20.3.284

[16] L. L. Gao, W. Xie, X. Yang, and S. W. Chan, "Effects of an interpersonal-psychotherapy-oriented postnatal program for Chinese first-time mothers: a randomized controlled trial," International Journal of Nursing Studies, vol.52, no.1, pp.22-29, (2015) DOI: 10.1016/j.ijnurstu.2014.06.006 